\title{
Multi-Criteria Assessment of Machining Processes for Turbine Disc Slotting
}

\author{
Fritz Klocke, Thomas Bergs, Benjamin Doebbeler, Marvin Binder and Martin Seimann *
}

Laboratory for Machine Tools and Production Engineering (WZL), RWTH Aachen University, 52074 Aachen, Germany; f.klocke@wzl.rwth-aachen.de (F.K.); t.bergs@wzl.rwth-aachen.de (T.B.);

b.doebbeler@wzl.rwth-aachen.de (B.D.); m.binder@wzl.rwth-aachen.de (M.B.)

* Correspondence: M.Seimann@wzl.rwth-aachen.de; Tel.: +49-241-80-28020

Received: 2 May 2018; Accepted: 23 May 2018; Published: 28 May 2018

\begin{abstract}
Many different process chains are possible to manufacture profiled grooves in turbine discs. Broaching with high speed steel tools is still state of the art today but as a consequence of the rising demand for aero engines, the disc manufacturers are striving for alternative high performance processes to increase both flexibility and productivity in the manufacturing of these safety critical features. Broaching machines are oftentimes at a bottleneck in the production of rotating turbine discs. Several other machining processes have been discussed in the context of slotting, such as broaching with carbide tools, milling, water jet machining, W-EDM and grinding. Within this paper a multi-criteria assessment approach is presented dealing with slotting processes. The assessment comprehends economical, ecological, flexibility and productivity criteria, and is based on data gathered with an aero engine OEM. The technological aspects such as tool life and productivities are based on real machining tests that have been carried out within the project HoFePro. The assessment is conducted for multiple profile shapes that represent different sizes and geometrical complexities of profiled grooves. The manufacturing processes within the assessment include broaching with HSS and carbide, milling with ceramics and carbide (side and end) as well as profile milling with carbide tools. The underlying workpiece material is a nickel-based alloy.
\end{abstract}

Keywords: profile slotting; multi-criteria assessment; conventional machining

\section{Introduction}

The demand for aero engines increases together with the demand for aircrafts. According to the latest Airbus Global Market Forecast from 2016, the global aircraft fleet will double in the period from 2016 to 2035 [1]. Facing this enormous demand for aero engines, the OEMs and suppliers of aero engines are striving for new high performance manufacturing processes that allow them to improve both productivity and flexibility.

Rotating discs are the centerpieces of the core aero engine. Whereas in the compressor part of the engine, the discs today are often made out of titanium alloys and have an integral design (Blade Integrated Disk-BLISK), the discs in the turbine exhibit profiled grooves to mount the turbine blades and consist of nickel-based alloys due to the high temperatures [2]. The differential design in the turbine part becomes necessary due to the requirement to internally cool the turbine blades.

The turbine blades are mounted on the disc via profiled grooves. The connection has to safely transmit the enormous centrifugal loads during service [3]. Manufacturing these profiled grooves is a difficult task. First, the nickel-based alloys applied in the turbine are difficult to machine, primarily due to their high hot hardness. Second, the turbine discs are highly safety critical, yielding high requirements regarding surface integrity [4]. Third, the tolerances of the profiled grooves are tight. 
Today, the state of the art manufacturing process for profiled grooves is broaching. Broaching is-in general-a highly productive, yet inflexible manufacturing process due to the high amount of cutting edges present on a broaching tool. Broaching, furthermore, is highly precise. The downsides of broaching comprehend the inflexibility due to the working principle and the fact that broaching machine tools are expensive, space demanding special machinery. Furthermore, when broaching profiled grooves in turbine discs, High Speed Steel (HSS) is still state of the art cutting material today, whereas it got replaced by high performance cutting materials such as tungsten carbide, CBN, ceramics or diamond, in the majority of machining applications. Due to the low hot hardness of HSS, the applicable cutting speeds in broaching of nickel-based alloys are not higher than 3-5 $\mathrm{m} / \mathrm{min}[5-7]$. The profiled grooves manufacturing process poses a bottleneck in the process chain of turbine disc production. Facing the high demand of new aero engines, producing companies are looking for alternative technologies to manufacture the profiled grooves, aiming for higher productivity and flexibility at the lowest cost.

\section{Process Chains for Slotting}

The considered process chains in this paper are depicted in Figure 1b. The manufacturing technologies are assigned to the sub steps of roughing, semi-finishing and finishing. Within this paper, roughing covers the process of removing the highest fraction of volume for the groove maintaining a distance of at least $0.5 \mathrm{~mm}$ to the final profile shape. Semi-finishing covers the process that precedes the finishing process and therefore regulates an acceptable allowance for the finishing process. During finishing, finally, the final shape is machined and thus very high demands regarding tolerance and surface integrity have to be met.

The assessment of the process chains will be conducted relative to the state of the art which is represented by process chain 1 (PC1), in Figure 1b. Broaching tools cover the entire manufacturing process including roughing, semi-finishing and finishing. A detailed analysis can be found in reference [8].

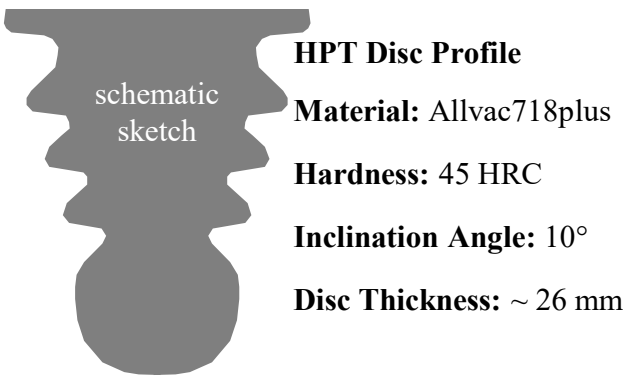

(a)

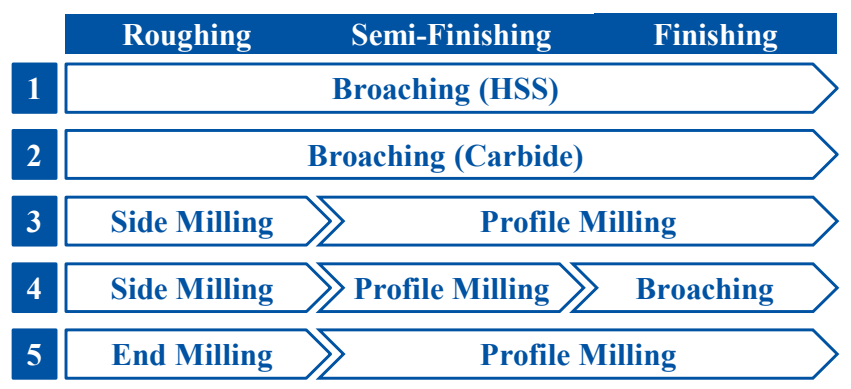

(b)

Figure 1. Profile and key characteristics (a), assessed process chains (b).

The state of the art is compared to broaching with cemented carbide (PC2). Using cemented carbide instead of HSS, considerably higher cutting speeds can be applied and the tool life can be increased at the same time. However, due to the lower fracture toughness of cemented carbide compared to HSS, the tools need to be designed carefully in order to avoid brittle fracture.

Furthermore, experimental investigations have been conducted using ceramic cutting inserts on a side milling tool for rough machining of profiled grooves. Ceramic cutting grades are highly wear resistant, yielding very high cutting speeds up to $\mathrm{v}_{\mathrm{c}}=1000 \mathrm{~m} / \mathrm{min}$ and therefore a highly productive process, cf. [8,9]. However, ceramic grades can only be used for rough machining due to their brittle wear behavior. Side milling cannot be applied to machine the undercuts of the profiled grooves and therefore, side milling is complemented with cemented carbide profile milling tools covering semi-finishing and finishing within PC3. 
Process chain 4 (PC4) is also based on a side milling roughing operation and profile milling for semi-finishing. For the finishing process, a broaching process was realized on a machining center with a translational axis. The benefit of this process chain is that a change of machine tools is not necessary within the process chain. Furthermore, the finishing technology remains a known and certified process. Process chain 5 (PC5) starts with ceramic end milling for roughing. Details on the experimental investigations can be found. The end milling process is combined with profile milling for the finishing operations.

\section{Underlying Assumptions}

The multi-criteria assessment of the process chains is conducted against economical, ecological, flexibility, technology readiness, and productivity criteria. The data used was provided by an aero engine OEM. The results are depicted in a relative shape due to confidentiality reasons.

The assessment of such a complex task is not trivial and the approach, including the assumptions, certain assessment values and the entire perspective, depends on the purpose of the assessment. However, within this paper one possible perspective is analyzed and the setup is described as transparent as the confidentiality restrictions allow. Furthermore, the result of the assessment depends on many details such as the shape and size of the profile, the material, the quantities of the discs, organizational boundary conditions, and many more.

\subsection{Economical Assessment}

For the economical assessment of the process chains, four cost categories have been taken into account. The labor costs, machine tool costs, tooling costs and the admission costs for the qualification of the manufacturing processes. All assessments have been conducted under the assumption that new machine tools are required and no restrictions in terms of floor space are given.

The labor costs per unit are calculated with the hourly labor costs and the time required, taking into account, that operators may operate multiple machine tools. For the machine hourly rate, the depreciation, the imputed interest costs, the maintenance costs, the energy costs and an overall cost rate to account for indirect costs for the floor space required, are used.

Tooling costs are calculated based on experimental investigations carried out within the project [8]. The assumed prices have been discussed with the tool suppliers and are in line with the market. However, due to confidentiality reasons they cannot be quantified within this paper. Multiple regrinding with the corresponding cost is taken into account for the broaching tools. The cost for regrinding and the quantity of possible regrinds was obtained by the OEM.

Since in aerospace industry for safety critical components, new manufacturing technologies require extensive admission; admission costs are taken into account for all the technologies not being state of the art. A number of produced discs have been assumed in order to relate the costs to a number of units. No further technology-independent fixed costs are taken into account for the economical assessment.

\subsection{Ecological Assessment}

The ecological assessment has been performed in accordance with the Life-cycle-assessment (LCA) approach "from cradle-to-gate" $[10,11]$. Since the assessment has comparative character, only the aspects varying between the process chains have been assessed. The chosen impact category is cumulated energy demand, a primary energy unit. The functional unit is one finished profiled groove.

The ecological assessment comprises the energy demand of the machine tool, an overall contribution for central units, illumination and climatization, as well as the consumed tools within the process. For reasons of simplicity, the connection power of the machine tools has been multiplied with a constant factor of 0.3 and the time required to manufacture one slot. The ecological assessment of the consumed metal cutting tools is based on the database probes as well as the literature [12-14]. For central units, illumination and climatization at a constant value of $70 \mathrm{~W} / \mathrm{m}^{2}$ has been used. 
To convert the demand of electrical energy into cumulated energy demand the factor of $2.586 \mathrm{~kJ}$ $\mathrm{CED} / \mathrm{kJ}$ has been used [12].

\subsection{Flexibility Assessment}

In order to assess a non-quantitative criterion like flexibility, a scoring approach was used. Therefore, a list of questions were formulated and weighted for the compared technologies, yielding a quantitative assessment result. The answering of the questions was done in discussion with an OEM.

Q1: How do you rate the expandability of capacities?

Q2: Is a change of machine tools necessary?

Q3: What are the fixed costs for the production of one piece?

Q4: Is special machinery required?

Q5: How long does the delivery of a tool set take?

Q6: How long does it take to manufacture an entirely new profile geometry?

Q7: How strong do you rate the influence of the profile shape on the technology?

In the scoring model, the highest rating for any question was 10, the lowest 1 . Additionally, the importance of the different questions was weighted by a factor. The main importance for the flexibility of a process was given to the expandability of the process chain (Q1). Therefore, this question was rated by a weight factor of 8 . The second point, which also has a main impact on the flexibility of a process chain, is the time from order until a new profile can be manufactured (Q6). In the case of conventional machining processes for every slot geometry, a special tool set at least for finishing, is required. To consider tool delivery times Q5 was rated with a weight factor of 5. For prototype manufacturing the manufacturing costs for a small number of slots are important (Q3). Furthermore, the technological feasibility for manufacturing any slot geometry is interesting (Q7). Therefore, both questions were rated with a weight factor of 4 . When building up new production capacities in times of the "green button process" the need for a change of the machine tools has to be taken into account (Q3). In this paper the change of the machine tool with regard to the flexibility was rated with a factor of 3. Broaching machines are special machine tools with long delivery times compared to standard five axis milling machine tools. For completion the flexibility assessment of the delivery time of a new machine tool is addressed in Q4. However, because of the service time of machine tools the new purchase is not daily business, which results in the weight factor of 1 .

Table 1 lists the results for the seven questions on flexibility for the process chains as well as the relative weight and the final score of the process chain.

Table 1. Flexibility assessment for the considered process chains.

\begin{tabular}{ccccccccc}
\hline & Q1 & Q2 & Q3 & Q4 & Q5 & Q6 & Q7 & Score \\
\hline PC1 & 3 & 10 & 6.68 & 1 & 1 & 1 & 2 & 3.25 \\
\hline PC2 & 3 & 10 & 1 & 7.8 & 1 & 4 & 1 & 3.86 \\
\hline PC3 & 8 & 10 & 9.45 & 10 & 10 & 10 & 5 & 8.77 \\
\hline PC4 & 8 & 10 & 10 & 10 & 10 & 10 & 5 & 8.84 \\
\hline PC5 & 8 & 10 & 9.22 & 10 & 10 & 1 & 5 & 7.00 \\
\hline Weight & 8 & 3 & 4 & 1 & 5 & 6 & 4 & \\
\hline
\end{tabular}

\subsection{Productivity}

For the assessment of the productivity of a certain process chain, the entire time required to manufacture the slots in a turbine disc is used. With a scoring method, the productivities are linearly assigned to values between 1 and 10 to compare the technology chains. Note that the productivity is not normalized to necessary investment costs for a machine tool. 
The general assumptions are listed in Table 2, on the left. The listed values affect multiple criteria. Technology-dependent assumptions are given within Table 3, on the right. For the machine life affecting the depreciation and the imputed interest costs, varying assumptions have been made for machining centers and a broaching machine based on the experience of the OEM. Analogously, the investment costs and the required floor space for the different types of machine tools vary significantly. The required personnel to operate the different types of machine tools varies due to the fact that the ratio between main time and setup time differs widely.

Table 2. General assumptions for the economical assessment.

\begin{tabular}{ccc}
\hline Variable & Unit & Value \\
\hline Interest rate & $\%$ & 10 \\
Labor Cost & $€ / \mathrm{h}$ & 50 \\
Indirect Costs Floor Space & $€ /\left(\mathrm{m}^{2 *} \mathrm{a}\right)$ & 180 \\
Admission cost & $\mathrm{k} €$ & 50 \\
Number of units for Admission & - & 500 \\
Energy costs & $€ / \mathrm{kWh}$ & 1000 \\
Energy demand & $\mathrm{kWh} / \mathrm{h}$ & 0.11 \\
Maintenance & $€ / \mathrm{a}$ & $30 \%$ of connection power \\
Shift system & $8 \mathrm{~h} / \mathrm{shift}, 3$ shifts $/ \mathrm{d}, 300 \mathrm{~d} / \mathrm{a}$ \\
Operators per Machine Tool & \multicolumn{2}{c}{0.5} \\
\hline
\end{tabular}

Table 3. Technology dependent assumptions for the economical assessment.

\begin{tabular}{cccc}
\hline Variable & Technology & Unit & Value \\
\hline \multirow{2}{*}{ Machine Life } & Broaching & $\mathrm{a}$ & 20 \\
& Milling & & 10 \\
\hline \multirow{2}{*}{ Invest } & Broaching & $\mathrm{k} €$ & 2400 \\
& Milling & & 1000 \\
\hline \multirow{2}{*}{ Required Space } & Broaching & $\mathrm{m}^{2} /$ machine & 80 \\
& Milling & tool & 40 \\
\hline
\end{tabular}

\subsection{Maturity}

A widespread method of quantifying technological maturity is Technology Readiness Levels (TRL), which was first introduced by the National Aeronautics and Space Administration (NASA). The scale reaches from TRL 1 (basic principles observed and reported) to TRL 9 (qualified flight proven technology). An interpretation of the European Space Agency (ESA) is given within ISO standard 16290. The assessment of the technology chains in terms of technological maturity was done in accordance with an OEM. The applied technologies have been assessed individually for the steps of roughing $(\mathrm{R})$, semi-finishing $(\mathrm{SF})$ and finishing $(\mathrm{F})$, compare Table 4 . The ratings have been averaged and the scores have been allocated linearly between 1 and 10 .

Table 4. Maturity assessment on the basis of TRL.

\begin{tabular}{cccccc}
\hline & R & SF & F & Average & Score \\
\hline PC1 & 9 & 9 & 9 & 9 & 10 \\
\hline PC2 & 5 & 4 & 4 & 4.33 & 4 \\
\hline PC3 & 4 & 4 & 4 & 4 & 3.6 \\
\hline PC4 & 4 & 4 & 4 & 4 & 3.6 \\
\hline PC5 & 4 & 4 & 4 & 4 & 3.6 \\
\hline
\end{tabular}


For PC1, the highest ratings are assigned since the technology is the current state of the art and many components are flight proven. For the majority of investigated technologies, the rating of TRL 4 was assigned, since the technologies have been analyzed in a laboratory environment. For rough broaching with cemented carbide, tests in the real operational environment have been performed legitimating a rating of TRL 5. Note that TRL 4 is the highest TRL that can be achieved within a scientific, laboratory-based development project.

\section{Case Study}

Within the case study, the assessment of the five process chains depicted in Figure $1 \mathrm{~b}$ was carried out for the profile shown in Figure 1a. The entire multi-criteria setup was chosen because it was explicitly not just the goal to determine the most cost efficient process chain but rather to enable disc manufacturers to cope with bottle neck situations in terms of capacity, floor space, time and other boundary conditions in times of rapidly rising demands.

The multi-criteria assessment is summarized in the web diagram, Figure $2 b$. It is obvious that no process chain dominates and therefore has the best rating out of all criteria. A very interesting alternative to the state of the art is broaching with cemented carbide (PC2). For the investigated profile and the chosen boundary conditions it stands out in terms of economical assessment and productivity since it allows increased cutting speeds and tool life, while at the same time using a well-established manufacturing process. It is also superior in terms of ecological assessment since indexable inserts are used and the ecological footprint of full body tools, as used in milling and HSS broaching, is worse. In terms of maturity, the state of the art excels, as it is the only process which is flight-proven today [15]. The technology chains involving milling have a lower economical rating for the investigated profile since the tooling costs are quite high and the tool life is limited. On the other hand, these process chains show advantages in terms of flexibility since no special machinery is required and the process chains do not require a change of machine tools during the machining sequence. Furthermore, the milling process chains promise a better extendibility of the capacities.

Note that the assessment is only valid for the assumptions and the underlying profile, and may vary significantly for a different setup.

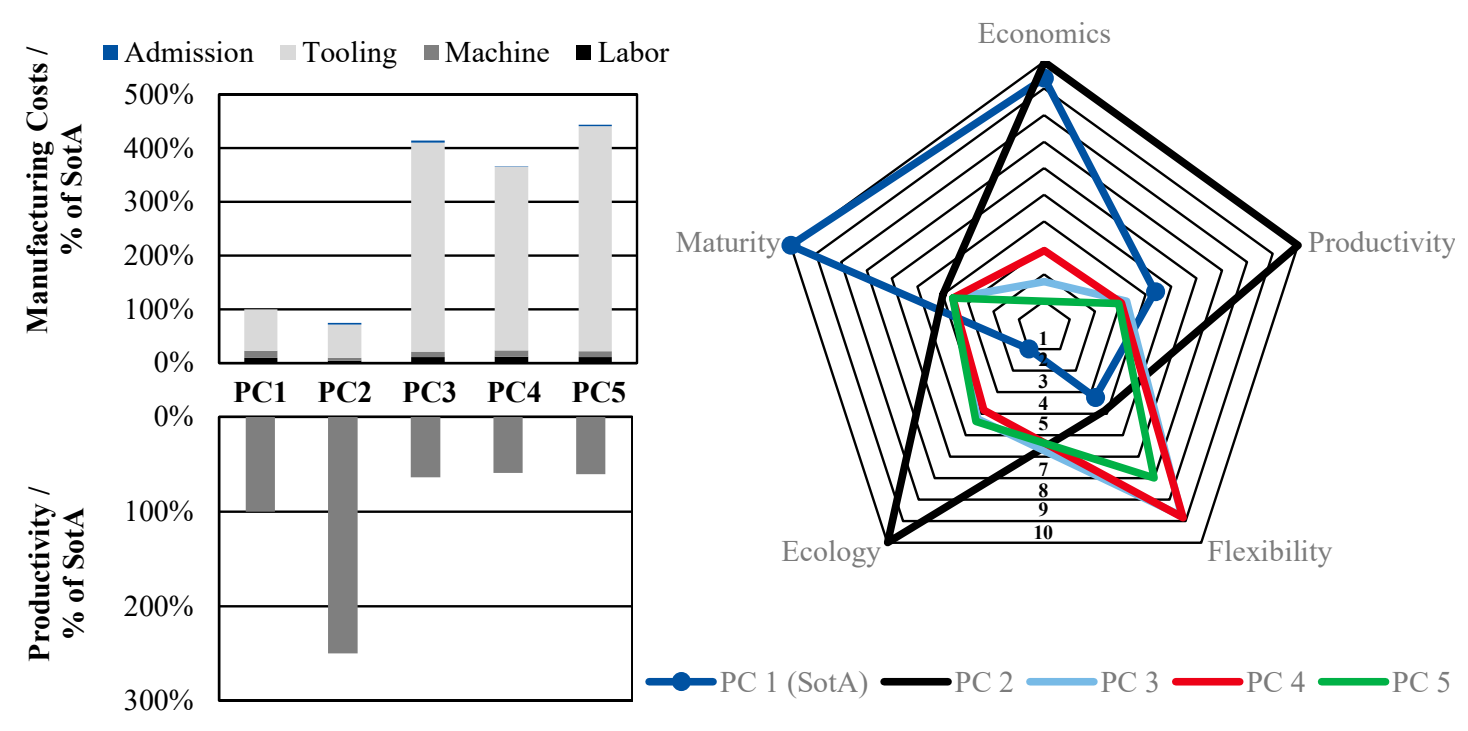

(a)

(b)

Figure 2. Results of the case study for the criteria productivity (a) and the multi-criteria assessment (b).

Nevertheless, the economic dimension in combination with the productivity of a certain technology chain takes up a major role in the assessment approach. Figure 2a depicts the productivity 
and manufacturing costs for the analyzed technology chains relative to the state of the art of broaching with HSS. The main observations for the investigated profile and the underlying assumptions are:

- The only conventional technology chain allowing increased productivity at a decreased cost is broaching with cemented carbide.

- The broaching test results this paper is based on were made in case of roughing and semi-finishing with broaches with screwed inserts [8] and in the case of finishing with full carbide tools. Of course there are some other tool concepts like tools with glued carbide inserts, which can be investigated in further research activities.

- For the conventional process chains for slot manufacturing the cost structure is dominated by tooling costs. This fact is caused by the poor machinability of the nickel-based alloys. Note that the machine hourly rates do not cover much of indirect costs.

- The highest costs are calculated for the technology chains based on milling (PC3-PC5).

- For the productivity, a distinct increase $(+150 \%)$ is shown for carbide broaching due to higher cutting speeds and higher tool life (less setup time).

- The milling process chains do not differ much in terms of productivity compared to the state of the art. This is mainly caused by semi-finishing and finishing. The roughing process is highly productive [8]. However, no broaching capacity is claimed.

- Based on the number of discs for the cost degression of the admission costs, cf. Table 2; admission costs play a minor role within this scenario.

\section{Discussion}

As underlined throughout the paper, the results cannot be generalized and represent an assessment with respect to the sketched assumptions and boundary conditions. Among other criteria, the size and the shape of the profile, the workpiece material and the lot size influence both the feasibility and the benefit of the different technology chains. Furthermore, technology chains with varying levels of maturity have been compared. Today, only the state of the art process has a clearance and is therefore flight proven. However, within a scientific research project technology readiness level 4 (TRL 4) can hardly be exceeded since tests in the real production environment are required. Especially finishing processes that are relevant for the service life of safety critical parts undergo an extensive qualification process. Non-conventional machining processes such as water jet and W-EDM have not been compared within this work because they are not flight proven and they comprehend an entirely different physical principle.

\section{Conclusions}

An assessment study has been carried out to compare conventional process chains for the manufacturing of profiled grooves against multiple criteria. None of the investigated process chains dominated. Whereas broaching with cemented carbide is the only investigated technology allowing for a simultaneous increase of productivity and decrease of costs, the process chains involving milling allow for an increased flexibility at higher costs. However, the presented results depend strongly on the underlying assumptions and boundary conditions and cannot be generalized.

Author Contributions: Conceptualization, F.K., T.B., B.D., M.S. and M.B.; Formal Analysis, M.B. and M.S.; Investigation, M.S..; Resources, F.K., T.B., B.D.; Writing-Original Draft Preparation, M.B. and M.S.; Writing-Review \& Editing, M.S.; Visualization, M.B.; Supervision, F.K.; Project Administration, B.D., M.B. and M.S. 
Acknowledgments: The authors gratefully acknowledge the financial support of the Federal Ministry of Education and Research (BMBF) and the project supervision of the Project Management Agency Karlsruhe (PTKA) within the project HoFePro (02PN2211).

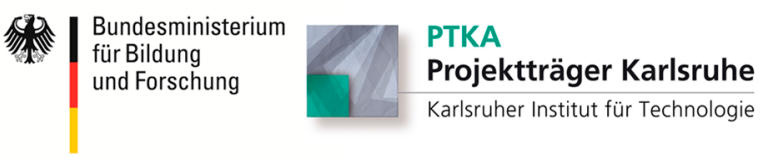

Conflicts of Interest: The authors declare no conflicts of interest.

\section{References}

1. Airbus. Airbus Global Market Forecast 2016-2035; Airbus: Toulouse, France, 2016.

2. Calleja, A.; Fernández, A.; Rodríguez, A.; de Lacalle, L.N.L.; Lamikiz, A. Turn-milling of blades in turning centres and multitasking machines controlling tool tilt angle. Proc. Inst. Mech. Eng. Part B J. Eng. Manuf. 2015, 229, 1324-1336. [CrossRef]

3. Royce, R. The Jet Engine, 5th ed.; Rolls-Royce Limited: London, UK, 2015.

4. Fernández-Valdivielso, A.; López de Lacalle, L.N.; Urbikain, G.; Rodriguez, A. Detecting the key geometrical features and grades of carbide inserts for the turning of nickel-based alloys concerning surface integrity. Proc. Inst. Mech. Eng. Part C J. Mech. Eng. Sci. 2016, 230, 3725-3740. [CrossRef]

5. Klocke, F.; König, W. Fertigungsverfahren 1: Drehen, Fräsen, Bohren, 8th ed.; Springer: Berlin, Germany, 2005-2008.

6. Vogtel, P.; Klocke, F.; Puls, H.; Buchkremer, S.; Lung, D. Modelling of Process Forces in Broaching Inconel 718. Procedia CIRP 2013, 8, 409-414. [CrossRef]

7. Denkena, B.; Tönshoff, H.K. (Eds.) Spanen: Grundlagen; Springer: Berlin, Germany, 2011.

8. Klocke, F.; Doebbeler, B.; Seimann, M.; Binder, M. Towards high productive roughing of profiled grooves in nickel based alloys. In Proceedings of the ASME Turbo Expo 2016, Seoul, Korea, 13-17 June 2016.

9. Klocke, F.; Lung, D.; Binder, M.; Seimann, M. High speed machining of nickel-based alloys. Int. J. Mechatron. Manuf. Syst. 2015, 8, 3-18. [CrossRef]

10. Guinee, J.B. Handbook on life cycle assessment operational guide to the ISO standards. Int. J. Life Cycle Assess. 2002, 7, 311. [CrossRef]

11. Deutsches Institut für Normung (DIN). Umweltmanagement-Ökobilanz-Grundsätze und Rahmenbedingungen; 13.020.10; ISO 14040:2006; Beuth Verlag GmbH: Berlin, Germany, 2009.

12. Umweltbundesamt. Prozessorientierte Basisdatenbank für Umweltmanagement-Instrumente (ProBas). Available online: http:/ / www.probas.umweltbundesamt.de/php/index.php (accessed on 16 May 2014).

13. Karpuschewski, B.; Kalhöfer, E.; Joswig, D.; Rief, M. Energiebedarf bei der Herstellung von Hartmetall-Wendeschneidplatten. Z. Wirtsch. Fabr. 2011, 106, 602-605. [CrossRef]

14. Karpuschewski, B.; Kalhöfer, E.; Joswig, D.; Rief, M. Energiebedarf für die Hartmetallherstellung. Z. Wirtsch. Fabr. 2011, 106, 496-501. [CrossRef]

15. M'Saoubi, R.; Axinte, D.; Soo, S.L.; Nobel, C.; Attia, H.; Kappmeyer, G.; Engin, S.; Sim, W.M. High performance cutting of advanced aerospace alloys and composite materials. CIRP Ann. 2015, 64, 557-580. [CrossRef]

(C) 2018 by the authors. Licensee MDPI, Basel, Switzerland. This article is an open access article distributed under the terms and conditions of the Creative Commons Attribution (CC BY) license (http:/ / creativecommons.org/licenses/by/4.0/). 